\title{
Head lice were also affected by COVID-19: a decrease on Pediculosis infestation during lockdown in Buenos Aires
}

\author{
Federico Galassi ${ }^{1}$ - Isabel Ortega-Insaurralde ${ }^{2}$. Victor Adjemian ${ }^{1} \cdot$ Paola Gonzalez-Audino ${ }^{1}$. Maria Inés Picollo ${ }^{1}$. \\ Ariel Ceferino Toloza $^{1}$
}

Received: 20 November 2020 / Accepted: 22 December 2020 / Published online: 6 January 2021

(C) The Author(s), under exclusive licence to Springer-Verlag GmbH, DE part of Springer Nature 2021

\begin{abstract}
Pediculosis is a worldwide disease affecting school-aged children produced by the presence of the head louse, Pediculus humanus capitis De Geer, an obligate ectoparasite on the human scalp feeding exclusively on blood. Transmission occurs primarily through direct physical head-to-head contact. In March 2020, the World Health Organization (WHO) declared the COVID-19 outbreak as a pandemic. COVID-19 is caused by SARS-CoV-2, a variant of the coronavirus. Therefore, on March 18, 2020, the Argentinean government established mandatory isolation for an indefinite period. This obligatory isolation interrupted regular classes avoiding direct contact between children, thus affecting the dispersal route of individuals and the evolution of head louse populations. In this study, we evaluated through an online survey how confinement affected the prevalence of lice during lockdown compared to the situation prior to confinement. The survey allowed to discriminate the different control strategies, the number of treatments, and the amount of insects recorded by parents. Data of 1118 children obtained from 627 surveys were analyzed. As the main result, it was observed that prevalence of lice decreased significantly from before (69.6\%) to during (43.9\%) COVID-19 lockdown. Moreover, head lice infestation was more effectively controlled in households with up to 2 children in comparison to households with 3 or more children. This is the first study that analyzed the prevalence of head lice during COVID-19 pandemic. In addition, this work demonstrated the impact of social distance in the population dynamics of head lice and how it could affect the control strategies in the future.
\end{abstract}

Keywords Covid-19 $\cdot$ Pediculosis $\cdot$ Head lice $\cdot$ Lockdown $\cdot$ Buenos Aires

Section Editor: Boris R. Krasnov

Federico Galassi

federico.g.galassi@gmail.com

Ariel Ceferino Toloza

atoloza@conicet.gov.ar

1 Centro de Investigaciones de Plagas e Insecticidas, Unidad de Investigación y Desarrollo para la Defensa, (UNIDEF-CONICET), Juan Bautista de La Salle 4397, B1603ALO, Villa Martelli, Buenos Aires, Argentina

2 Grupo de Neuroetología de Insectos Vectores, Laboratorio Fisiología de Insectos, Instituto Biodiversidad y Biología Experimental y Aplicada (IBBEA, UBA-CONICET), Departamento Biodiversidad y Biología Experimental (DBBE), Facultad de Ciencias Exactas y Naturales, Universidad de Buenos Aires, Ciudad Universitaria, Intendente Güiraldes 2160, C1428EGA Buenos Aires, Argentina

\section{Introduction}

Pediculosis capitis is one of the most common parasitic diseases among children worldwide, caused by the human head louse Pediculus humanus capitis De Geer,1767 (Anoplura: Pediculidae). This exclusive ectoparasite that feeds on blood and spends its entire life cycle on its host head has been associated with humans since the origin of humankind (Reed et al. 2004). Combining both epidemiological and laboratory studies, head lice can transmit pathogens to their host under favorable epidemiological conditions, although its vectorial capacity is weaker in comparison to body lice (Pediculus humanus humanus) (Boumbanda-Koyo et al. 2020). However, bacterial secondary infections may appear caused by the scratching of the head scalp due to the blood feeding and excretory behavior of these parasites. Additionally, head louse infestations can affect children's behavior, school performance, and sleep quality due to the discomfort of scratching (Bailey and Prociv 2002). Many people manifest with head lice as more of an 
emotional and physiological problem rather than a clinical one.

Transmission occurs primarily through direct head-tohead contact and the main routes of infestation occur between social and familiar contact, as well as between parents and children. Thus, the school "environment" (social interactions among children) is a valuable resource of transmission of pediculosis (Mumcuoglu et al. 2009). Risks factors for acquiring pediculosis are determined by several factors like the number of children per family, the local customs and kinds of social contacts, the lack of healthcare systems, and the socioeconomic status of the family (Mumcuoglu et al. 2020). Head lice are more prevalent among children 3 to 14 years attending elementary schools and childcare institutes. Girls are 2-4 times more infested than boys partly due to their long hair and their social interactions (more tendency to play games favoring head to head contacts) (Toloza et al. 2009).

The prevalence of infestation in different countries varies according to the population features and the control methods mainly used. For example, in the Americas, the prevalence varies from 2 to $80 \%$ being the countries of South America with the highest prevalence of lice (Falagas et al. 2008). A study at our laboratory, carried out on 1856 children from schools of Buenos Aires, showed that $30 \%$ of the children were infested with head lice (Toloza et al. 2009). More recently, another study using a twofold approach (data collected from elementary schools and children's homes combined with the predictions of a mathematical model) revealed that the overall head lice prevalence varied from 26 to $69 \%$ (Toloza et al. 2018).

The two main strategies against the spread of pediculosis are individual head lice control and prevention of head lice transmission. In Argentina, the main treatments consist of combing alone or in combination with over-the-counter (OTC) pediculicides (Gallardo et al. 2012, 2013). The overuse of products containing permethrin in the last decades has led to the development of high levels of resistance (Picollo et al. 2000; Toloza et al. 2014).

In March 2020, the World Health Organization (WHO) declared the COVID-19 outbreak as a global pandemic (WHO 2020). COVID-19 is caused by SARS-CoV-2, a variant of coronavirus, causing lung, intestinal, cardiac, and neurological damage that emerged in China (Zhu et al. 2020). As a sanitary method, in March, the Argentinean government established strict lockdown for an indeterminate time. The mandatory social distancing does not allow direct contact among people from different houses and includes isolation of symptomatic individuals and restrictions on leaving home except for essential reasons (Argentine Government, 297/ 2020). Because of it, school classes were interrupted and all children were sent home and received virtual classes through different educational platforms.
The space-temporal distribution of hosts can influence the prevalence of parasites, in particular head lice. Theoretically, prevalence of infestations increases with rising host density due to the increased probability of parasite transmission (Krasnov et al. 2002; Altizer et al. 2003; Stanko et al. 2006). Head lice may also be considered as a species living on discrete habitat patches represented by groups of closely interacting human hosts. The metapopulation theory implies that for human-head louse interaction, isolated and small habitat patches consisting of few human hosts should have lower head louse load than less isolated and larger patches with many hosts (Hanski and Thomas 1994; Hanski 1999). This would be due to higher extinction and lower colonization/ recolonization rates in the smaller patches.

Under the particular and unique social circumstances triggered by the COVID-19 lockdown that disrupt human interactions at different levels, we were interested in how this situation could affect head lice transmission and prevalence among children of the city of Buenos Aires. Therefore, the aim of this work was to study the head louse infestation control dynamics/prevalence before and during COVID 19 lockdown in the Metropolitan Area of Buenos Aires (MABA). More specifically, by means of surveys directed to families of this location, we determined the incidence of spatial distribution of human hosts in combination with individual and household characteristics on head louse prevalence.

\section{Materials and methods}

\section{Study area}

The study was a cross-sectional descriptive study that consisted of questionnaires with epidemiological questions directed to families of the MABA, Buenos Aires, Argentina (Fig. 1). The MABA cover an area of $13,934 \mathrm{~km}^{2}$ with 40 municipalities and has the largest number of habitants in the country, representing 37\% of the population of Argentina (INDEC 2010).

\section{Study design and participants}

The study was launched on June 2, 2020, and data collection ended on July 28, 2020, under a strict lockdown period. Argentina is the country with the longest lockdown, with 180 days of strict confinement (Argentina decree 576/2020).

Participants were recruited by distributing through different social media an invitation to participate. Households with school-age children resident in the MABA and keeping social distancing due to COVID-19 were eligible to participate. Participants were directed to an encrypted data website where they indicated their consent to participate after reading an 
Fig. 1 Map showing the municipalities of the Metropolitan Area of Buenos Aires, Argentina, that participated in our study to investigate head louse prevalence before and during COVID-19 lockdown

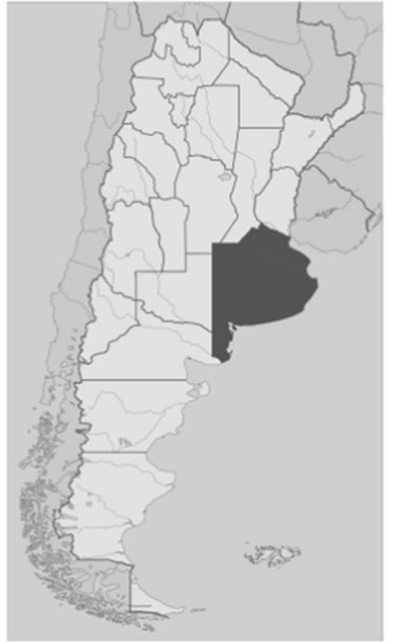

Argentina

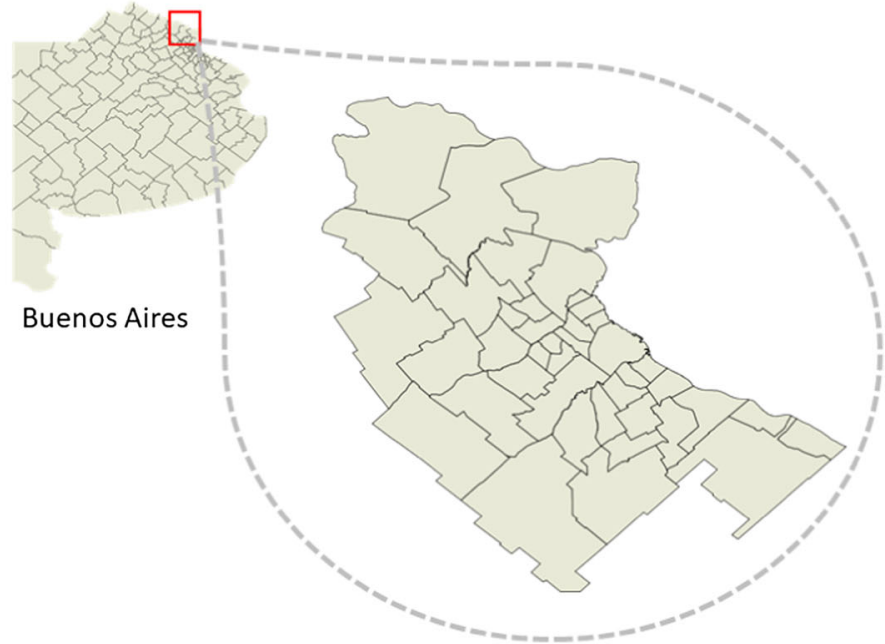

MABA (Metropolitan Area of Buenos Aires) information sheet (Google Forms, https://forms.gle/ dm4ivz2mw3ZtHErG6).

Questionnaire design The development of the questionnaire was based on experimental evidence provided by researchers and existing findings in the literature. This resulted in thirteen closed and open questions. They were structured into the following sections: characteristics of the household including number of rooms, style of the household, total people per home, and children per home. The age of the children was also surveyed. Besides, the questionnaire contained epidemiological questions about previous louse infestations at home and the frequency of the control methods used. The positive infestation of lice was defined as finding at least one live louse and/or nits on children's heads (Burgess 2009). In case of the participants answered that pediculosis was observed at home during isolation, they were requested to indicate the method of control used to remove the lice, number of lice removed per control, and number of inspections and treatments needed to remove all the lice.

\section{Data analysis}

The data were analyzed by means of chi-square test to establish the relationship between head louse prevalence in the surveyed children and the social isolation due to COVID-19. Odd ratios were computed to test association of prevalence of pediculosis before and during lockdown. Also, a Chi-square test $\left(\chi^{2}\right)$ was performed to study the influence of number of children and people per home and the number of rooms of the house in the head louse prevalence before and during lockdown. Statistical significance was considered at $P<0.05$. The statistical analysis was performed with the InfoStat program package (InfoStat Group, 2017).

\section{Results}

Out of 627 questionnaires, a total of 1118 children participated in the study. Total answers regarding frequency of control of head louse infestations and the number of insects usually detected before lockdown are found in Table 1 . The majority of the children surveyed were inspected for lice once a week, followed by those inspected after head scratches were observed. These two cases represented more than $70 \%$ of the studied cases. In terms of the number of lice removed, most of the children had light ( $<10$ head lice/head) or no infestation. Only $15.4 \%$ of the surveys reported high head louse infestation (>10 individuals per head).

As the main result, prevalence of lice (the proportion of positive surveys) decreased significantly from before $69.6 \%$ $(N=779)$ to during 43.9\% ( $N=491)$ COVID-19 lockdown (Fig. 2). Moreover, the statistical analysis showed that there was a significant difference $(P<0.001)$ between these two periods. The relationship between the number of children per home and the prevalence of head lice was also studied. The percentage of head louse infestations (expressed as number of children/home) decreased during lockdown (Fig. 3). If we observe the data corresponding to one and two children per home, the tendency of the percentage of head louse infestations was higher before than during lockdown. In addition, our analysis suggested that during confinement, in a house with up to 2 children, the control of pediculosis was possible. On the other hand, in households with 3 to 4 children, the prevalence of pediculosis was rather similar $(P>0.05)$ to the percentage surveyed before the lockdown, probably due to deficits in the control efficacy.

The number of rooms of the house of surveyed participants, an epidemiological feature that can inform host habits and degree of aggregation, was also studied in relation to the head louse prevalence before and during lockdown. Of this, head 
Table 1 Frequency of inspection and number of removed lice in the studied children before lockdown due to COVID-19. DK do not know

\begin{tabular}{llllllll}
\hline $\begin{array}{l}\text { Frequency of head } \\
\text { lice inspection }\end{array}$ & \multicolumn{6}{l}{ Number of insects removed } \\
\cline { 2 - 7 } & Nits & 1 to 5 & 5 to 10 & $>10$ lice & None & $\begin{array}{l}\text { Total } \\
\text { children }\end{array}$ & $(\%)$ \\
\hline Once a day & 23 & 104 & 42 & 28 & 73 & 270 & 24.2 \\
Once a week & 48 & 126 & 83 & 70 & 80 & 407 & 36.4 \\
After scratching & 50 & 90 & 58 & 74 & 149 & 421 & 37.7 \\
DK & 1 & 0 & 0 & 0 & 19 & 20 & 1.8 \\
Total children & 122 & 320 & 183 & 172 & 321 & 1118 & \\
$(\%)$ & 10.9 & 28.6 & 16.4 & 15.4 & 28.7 & & 100 \\
\hline
\end{tabular}

louse infestations were significantly higher before confinement, but no tendency was found between the number of rooms and the prevalence of lice $\left(\chi^{2}=2.59 ; P=0.62\right)$. Similarly, the number of household members (either adults or children) was also studied in their relationship with the prevalence of head lice. Significant differences were found between before and during lockdown $\left(\chi^{2}=53.25\right.$; $P<0.0001)$. However, the number of people sharing a home did not affect statistically the prevalence of head louse infestations.

The methods of treatments of pediculosis capitis during COVID-19 confinement are shown in Table 2. Variables such as the type of control method, number of lice removed, and inspection and treatments performed to remove all the lice were surveyed. Concerning to the most often selected method of control, combing alone or in combination with pediculicides were the most used strategies to remove lice (73.7\%). Moreover, $60 \%$ of children were reported to possess light infestation ( $<10$ individuals/head). Conversely, a low percentage of children $(8.1 \%)$ had a severe infestation intensity (> 50 individuals/head). Most children were inspected and treated against lice only once or twice.

\section{Discussion}

The present study was designed to evaluate the effect of the coronavirus disease 2019 (COVID-19) obligatory confinement on the prevalence of head lice in children from the Metropolitan Area of the City of Buenos Aires (MABA). Our results showed that the prevalence of pediculosis decreased significantly during COVID-19 lockdown. Pediculosis capitis is a common public health problem, and the "school environment" favors children to the spread of lice, which can then be transmitted to family members (Flinders and De Schweinitz 2004, Leung et al. 2005). The context of obligatory isolation or lockdown allowed us to predict the re-infestation cycle-dynamic of lice at home gaining insights into possible control problems within the domestic environment.

As far as we know, this is the first work that study head lice infestation during pandemic COVID-19. Our data showed that before the confinement, the prevalence of head louse infestations was $69 \%$. Despite the present data were estimated from surveys, the obtained values were similar to those previously reported from Buenos Aires (Toloza et al. 2009, 2018). For example, Toloza et al. (2009) analyzed a total of 1856 children aged 3-13 years old from eight elementary schools of Buenos Aires with head louse prevalence between $16 \%$ and $54 \%$. More recently, a study performed in 237 children from an elementary school and a children's home of the MABA area revealed that the overall prevalence varied from 26 to $69 \%$ (Toloza et al. 2018). This tendency has also been reported by many authors in different countries (Hatam-Nahavandi et al. 2020). According to this multifactorial study, Argentina has the highest prevalence in the Americas with an overall value of $51 \%(\mathrm{CI} 95 \%=0.35-0.67)$. The variation in the
Fig. 2 Prevalence of pediculosis capitis before and during COVID19 lockdown

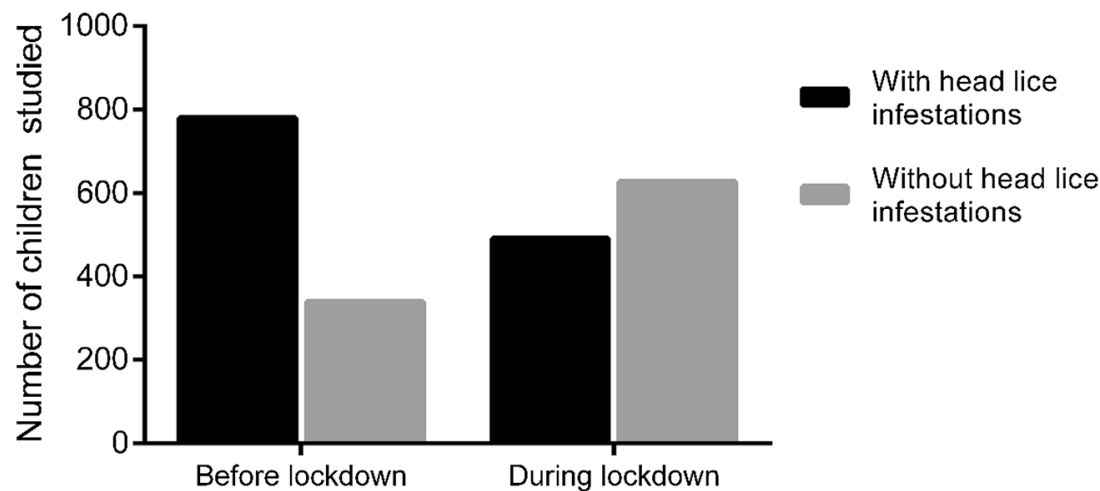


Fig. 3 Prevalence of head louse infestations before and during lockdown in homes with different numbers of children

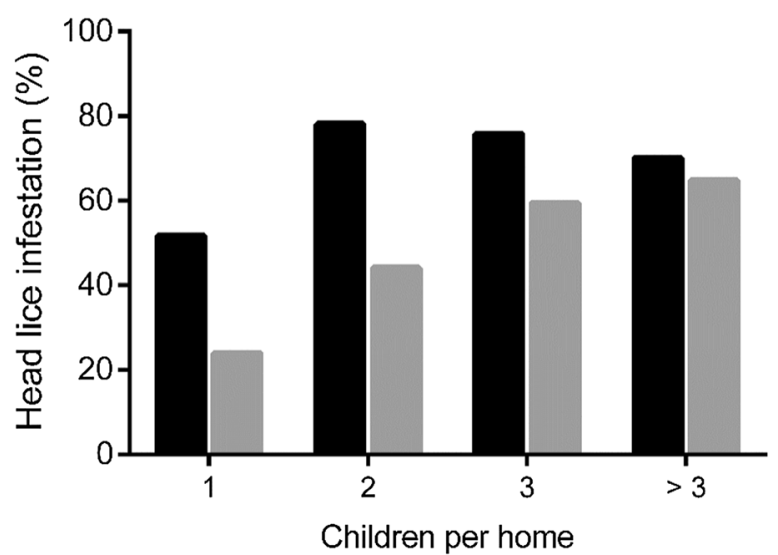

Before lockdown

During lockdown

infestation rate might be explained by many factors such as lice control policy, eradication strategies, number of head-tohead contacts, personal hygiene, and socio-economic status (Mumcuoglu et al. 2020).

Although the prevalence of head louse infestations decreased during confinement, our data showed high levels of infestations in the households. Several epidemiological factors can explain this outcome such as the way to consider active infestations and the efficacy of control methods. Our study considered active infestation when parents observed nits near the scalp (Williams et al. 2001). However, examination of more than 15,000 children in Israel, by means of louse-combing, revealed that $11-19 \%$ of the children were infested with living lice and nits, while a further $22-30 \%$ had only nits

Table 2 Control methods used by the surveyed participants, number of lice removed, and number of treatments performed during lockdown

\begin{tabular}{|c|c|}
\hline Variable & $\begin{array}{l}\text { Number of } \\
\text { children }(\%)\end{array}$ \\
\hline \multicolumn{2}{|l|}{ Control method } \\
\hline Metal comb & $213(43.4)$ \\
\hline $\begin{array}{l}\text { Metal comb and } \\
\text { pediculicide }\end{array}$ & $149(30.3)$ \\
\hline Pediculicide & $11(2.4)$ \\
\hline $\begin{array}{l}\text { Vinegar and metal } \\
\text { comb }\end{array}$ & $101(20,8)$ \\
\hline Vinegar & $0 \quad(0)$ \\
\hline Other & $17(3,6)$ \\
\hline \multicolumn{2}{|l|}{ Removed head lice } \\
\hline $1-10$ & $295(60,1)$ \\
\hline $11-50$ & $156(31,8)$ \\
\hline$>50$ & $40(8,1)$ \\
\hline \multicolumn{2}{|c|}{$\begin{array}{l}\text { Inspection and treatments } \\
\text { performed to remove all lice }\end{array}$} \\
\hline 1 & $113(23,0)$ \\
\hline 2 & $138(28,2)$ \\
\hline 3 & $95(19,3)$ \\
\hline 4 & $37(7,5)$ \\
\hline$>4$ & $108(22,0)$ \\
\hline
\end{tabular}

(Mumcuoglu 1999). Approximately $80 \%$ of these children had nits near the scalp, which would indicate that they had been unsuccessfully treated for lice and a possible re infestation. This is probably the reason that in most epidemiological studies, the presence of nits is a criterion for head louse infestations (Meinking and Taplin 2003).

Regarding control methods, inefficacy to decrease head louse infestations can be due to the use of pediculicides with changes in formulation or ingredient sourcing over the years, improper use of them, i.e., applying highly diluted pediculicide formulations, the use of alternative remedies with non-certified efficacy, and the spread of insecticide resistance (Mumcuoglu et al. 2020). Another factor that contributes to underestimate active infestations is the direct visual examination as it is particularly difficult to find by the lice infesting a child scalp by manual examination when the parasite load is low (Mumcuoglu et al. 2001). Our results showed that the majority of children were reported to possess light infestation (1-5 head louse); therefore, we supposed that this might be the main difficulty of parents in detecting additional individuals and eradicated them in household. Although these data were in confinement, similar results were found in other studies. For example, $78 \%$ of infested children from Israel had fewer than 10 lice on their scalp, $18.7 \%$ had 11-20 lice, and only $3.3 \%$ had more than 20 lice (Mumcuoglu et al. 1990). Moreover, infestations with high parasite load were low during the lockdown, only $8.1 \%$ had more than 50 lice per control or treatment. Similar results from Argentina showed that a low percentage children harbored a high number of lice on their heads (Toloza et al. 2009, 2018). This agrees with the wellknown general feature of nearly all host-parasite systems, where most of the hosts carry low or light parasite loads while a small number of highly infested individuals carry the majority of the parasite population (Anderson and May 1978; Poulin 1993).

In the present study, we found that the risk of spreading head lice during lockdown increased with the number of children present in the household rather than with the total household members. Households with more than two children are 
likely to have higher total contact rates than those with one or two children, increasing the risk of head louse re-infestations. Other studies have also found that head louse transmission increased with the number of household members (Willems et al. 2005; Balcioglu et al. 2007; Motovali-Emami et al. 2008). However, through our questionnaire, we were unable to detect that total number of household members (children and/or adults) positively correlated with the prevalence of pediculosis during confinement. Increased host density would synergize the effect of closeness and higher interaction among children resulting in increased probability of parasite dispersal. This prediction falls within the metapopulation theory: parasites infesting different host individuals are analogous to free-living organisms inhabiting discrete patches, and the percentage of occupation of the latter increases with the decrease of patch isolation (Thomas and Hanski 1997). This correlation between host density and prevalence of infestation has been supported by empirical studies that host population density and average parasite abundance were strongly positively correlated (Arneberg et al. 1998).

The survey of the present work also included questions regarding the control methods applied during the confinement. The most selected method was the louse-combing, either alone or combined with over-the-counter (OTC) pediculicides. Similarly, in a study performed in Brazil $44 \%$ of the parents choose combing as the main control strategy (Silva et al. 2008). It was demonstrated that in light infestations, 100 and $97 \%$ of the head lice (either adults or nits) were successfully removed from boys and girls; respectively (Toloza et al. 2018). Thus, combing demonstrated that it could be a successful strategy against pediculosis. Also, the selection by parents of this option might be due to several causes: (a) higher cost of pediculicides (in relation to metal combs), (b) ineffective pediculicides or repellents (due to insecticide resistance issues), and (c) obligatory confinement modified human movements since only adult people were allowed to leave home for specific and limited purposes like getting food and medicine. Moreover, the number of treatments necessary to eradicate head lice from household varied probably due to the above mentioned reasons and that individual susceptibility of some infested asymptomatic children due to insensitization to saliva, thus not being detected by their parents allowing to spread lice if control was effective and frequently performed (Malcolm and Bergman 2007).

Finally, the present study allowed to us to understand the prevalence of louse infestations in Buenos Aires before and during the COVID-19 lockdown in order to understand the population dynamics of head lice infestation. However, it is important to note that the current study has some limitations and bias, and hence, the findings should be carefully interpreted. For example, the inspection method of head lice might be considered as a variable method of detection of pediculosis since parents perception of head lice may vary greatly. Despite the relative differences among the studied categories of each variable, the main results are clear and it is highly unlikely they would vary. Thus, the main conclusions from the present study indicate that pediculosis was affected by COVID-19 lockdown due to the low movement of children outside their homes and the absence of regular classes.

Contrary to the head lice prevalence, there was an explosion in the mite Sarcoptes scabiei cases during COVID-19 pandemic. A research study reported a sudden rise of scabies two month after the first case of COVID-19 in Turkey (Kutlu et al. 2020). The authors attribute this to the "stay-at-home" policy that is very crucial to control the outbreak of scabies. The incubation period in scabies is on average of 2-3 weeks (may have no symptoms but still spread mites); hey can live for 3 days outside the human body and remain infectious up to 10 days in hyperkeratotic crusts (Mumcuoglu et al. 2009). The primary contributing factors in contracting scabies mites seem to be the lack of hygiene and overcrowded living conditions. Because of this, several reasons might explain the increasing number of scabies-related patients during COVID-19 pandemic: (a) the temporary workplace closure allowed patients to migrate from urban to rural areas where scabies are more frequently reported, (b) the increasing close contact of persons remaining at home promoted the contagious between individuals, and (c) the high hospital bed turnover rate lead to hospitals to be a significant primary source of scabies (Kutlu et al. 2020). Despite scabiosis and pediculosis might have similar symptoms during the initial stage of infestation, the diagnosis and treatment of scabies mites are very different than those for pediculosis. Finally, head louse and scabies mites infestations continue to be prevalent in our society. The prolonged incubation times of around 4 to 8 weeks before the appearance of pruritus attending head lice infestation and the delayed-type hypersensitivity reaction to scabies infestation make early diagnosis of these ectoparasites difficult and close human contact increase the spreading of these infestations (Mumcuoglu et al. 2009).

In conclusion, this work showed for the first time that the prevalence of pediculosis decreased during self-isolating/social distancing in the context of COVID-19 pandemic. The number of children per home was the main factor associated with significant levels of head louse infestations during lockdown. Moreover, self-isolation allowed us to make an analysis of head louse populations dynamic within a small sample of human hosts provided through a survey providing with knowledge about the population dynamics of these parasites to take preventive measures in the future.

Acknowledgments Our thanks to the parents who completed the online survey. We want to thank Dra. Victoria Matozo for helping us with the revision of the questionnaire. P.G.A, M.I.P and A.C.T are researchers from the National Council for Scientific and Technological Research 
(CONICET), Argentina. V.A is a Phd student from CONICET. F.G and I.O.I are postdoc from CONICET, Argentina. This study received financial support by CONICET PIP2016-0198CO to ACT, and to the ANPCyT PICT 2016-1431 to MIP and PGA. The experiments in this work comply with the current law of Argentina.

Funding This study received financial support by CONICET PIP20160198CO to ACT, and to the ANPCyT PICT 2016-1431 to MIP and PGA.

\section{References}

Altizer S, Nunn CL, Thrall PH, Gittleman JL, Antonovics J, Cunningham AA, Dobson AP, Ezenwa V, Jones KE, Pedersen AB, Poss M, Pulliam JRC (2003) Social organization and parasite risk in mammals: integrating theory and empirical studies. Annu. Rev Ecol Evol Syst 34:517-547. https://doi.org/10.1146/annurev.ecolsys.34. 030102.151725

Anderson R, May R (1978) Regulation and stability of host-parasite population interactions: I. Regulatory Processes. J Anim Ecol 47: 219-247. https://doi.org/10.2307/3933

Arneberg P, Skorping A, Grenfell B, Read AF (1998) Host densities as determinants of abundance in parasite communities. Proc R Soc Lond B 265:1283-1289. https://doi.org/10.1098/rspb.1998.0431

Bailey A, Prociv MP (2002) Head lice appearance and behaviour: implications for epidemiology and control. Healthcare Infection 7:62-71. https://doi.org/10.1071/HI02062

Balcioglu IC, Kurt O, Limoncu ME, Dinc G, Gumus M, Kilimcioglu AA, Kayran E, Ozbilgin A (2007) Rural life, lower socioeconomic status and parasitic infections. Parasitol Int 56:129-133. https://doi.org/10. 1016/j.parint.2007.01.005

Boumbanda-Koyo CS, Mediannikov O, Amanzougaghene N, OyegueLiabagui SL, Karl Imboumi-Limoukou R, Raoult D, Lekana-Douki FF (2020) Molecular identification of head lice collected in Franceville (Gabon) and their associated bacteria. Parasit Vectors 13:410. https://doi.org/10.1186/s13071-020-04293-x

Burgess IF (2009) Current treatments for pediculosis capitis. Curr Opin Infect Dis 22:131-136. https://doi.org/10.1097/QCO.0b013e328322a019

Falagas ME, Matthaiou DK, Rafailidis PI, Panos G, Pappas G (2008) Worldwide prevalence of head lice. Emerg. Infect. Dis 14:14931494. https://doi.org/10.3201/eid1409.080368

Flinders DC, De Schweinitz P (2004) Pediculosis and scabies. Am Fam Physician 15(69):341-348

Gallardo A, Mougabure-Cueto G, Vassena C, Picollo MI, Toloza AC (2012) Comparative efficacy of new commercial pediculicides against adults and eggs of Pediculus humanus capitis (head lice). Parasitol Res 110:1601-1606. https://doi.org/10.1007/s00436-0112668-x

Gallardo AB, Toloza AC, Vassena C, Picollo MI, Mougabure-Cueto G (2013) Comparative efficacy of commercial combs in removing head lice (Pediculus humanus capitis) (Phthiraptera: Pediculidae). Parasitol Res 112:1363-1366. https://doi.org/10.1007/s00436-0123208-z

Google forms. URL: https://forms.gle/dm4ivz2mw3ZtHErG6

Hanski I (1999) Metapopulation Ecology, 1st edn. Oxford University Press, New York, USA

Hanski I, Thomas CD (1994) Metapopulation dynamics and conservation: a spatially explicit model applied to butterflies. Biol Conserv 68:167-180. https://doi.org/10.1016/0006-3207(94)90348-4

Hatam-Nahavandi K, Ahmadpour E, Pashazadeh F, Dezhkam A, Zarean M, Rafiei-Sefiddashti R, Salimi-Khorashad A, Hosseini-Teshnizi S, Hazratian T, Otranto D (2020) Pediculosis capitis among school-age students worldwide as an emerging public health concern: a systematic review and meta-analysis of past five decades. Parasitol Res 119:3125-3143. https://doi.org/10.1007/s00436-020-06847-5

INDEC (2010) https://www.indec.gob.ar/indec/web/Nivel4-Tema-2-24119. Accessed 22 April 2020

Krasnov B, Khokhlova I, Shenbrot G (2002) The effect of host density on ectoparasite distribution: an example of a rodent parasitized by fleas. Ecology 83:164-175. https://doi.org/10.1890/0012-9658(2002) 083[0164:TEOHDO]2.0.CO;2

Kutlu Ö, Günes R, Coerdt K, Khachemoune MA (2020) The effect of the "stay-at-home" policy on requests for dermatology outpatient clinic visits after the COVID-19 outbreak. Dermatol Ther. 33:e13581. https://doi.org/10.1111/dth.13581

Leung A, Fong J, Pinto-Rojas A (2005) Pediculosis capitis. J. Pediatr. Health Care 19:369-373. https://doi.org/10.1016/j.pedhc.2005.07. 002

Malcolm CE, Bergman JN (2007) Trying to keep ahead of lice: a therapeutic challenge. Skin Ther letter 11:1-6

Meinking TL, Taplin D. Infestations. In: Schachner LA, Hansen RC (2003) Pediatric Dermatology, 3rd edn., Mosby Inc Publisher New York, pp 1141-1180.

Motovali-Emami M, Aflatoonian MR, Fekri A, Yazdi M (2008) Epidemiological aspects of Pediculosis capitis and treatment evaluation in primary-school children in Iran. Pak J Biol Sci 11:260-264. https://doi.org/10.3923/pjbs.2008.260.264

Mumcuoglu KY (1999) Prevention and treatment of head lice in children. Paediatr Drugs 1:211-218. https://doi.org/10.2165/00128072199901030-00005

Mumcuoglu KY, Miller J, Gofin R, Adler B, Ben-Ishai F, Almog R, Kafka D, Klaus S (1990) Epidemiological studies on head lice infestation in Israel. I. Parasitological examination of children. Int J Dermatol 29:502-506. https://doi.org/10.1111/j.1365-4362.1990. tb04845.X

Mumcuoglu KY, Friger M, Ioffe-Uspensky I, Ben-Ishai F (2001) Louse comb versus direct visual examination for the diagnosis of head louse infestations. Pediatr Dermatol 18:9-12. https://doi.org/10. 1046/j.1525-1470.2001.018001009.x

Mumcuoglu KY, Gilead L, Ingber A (2009) New insights in pediculosis and scabies. Expert Rev Dermatol. 4:285-302. https://doi.org/10. 1586/edm.09.18

Mumcuoglu KY, Pollack RJ, Reed DL, Barker SC, Gordon S, Toloza AC, Picollo MI, Taylan-Ozkan A, Chosidow O, Habedank B, Ibarra J, Meinking TL, Vander Stichele RH (2020) International recommendations for an effective control of head louse infestations. Int J Dermatol. https://doi.org/10.1111/ijd.15096

Picollo MI, Vassena C, Mougabure Cueto G, Vernetti M, Zerba E (2000) Resistance to insecticides and effect of synergists on permethrin toxicity in Pediculus capitis (Anoplura: Pediculidae) from Buenos Aires. J Med Entomol 37:721-725. https://doi.org/10.1603/00222585-37.5.721

Poulin R (1993) The disparity between observed and uniform distributions: a new look at parasite aggregation. Int. J. Parasitol 23:937944. https://doi.org/10.1016/0020-7519(93)90060-C

Reed DL, Smith VS, Hammond SL, Rogers AR, Clayton DH (2004) Genetic analysis of lice supports direct contact between modern and archaic humans. PLoS Biol 2:e340. https://doi.org/10.1371/ journal.pbio.0020340

Silva L, Alencar RA, Madeira NG (2008) Parental perception of head lice Silva, Alencar, and Madeira Tropical medicine rounds Survey assessment of parental perceptions regarding head lice. Int J Dermatol 47:249-255. https://doi.org/10.1111/j.1365-4632.2008.03570.x

Stanko M, Krasnov BR, Morand S (2006) Relationship between host abundance and parasite distribution: inferring regulating mechanisms from census data. J Anim Ecol 75:575-583. https://doi.org/ 10.1111/j.1365-2656.2006.01080.x 
Thomas CD, Hanski IA (1997). Butterfly metapopulations in Metapopulation biology. Ecology, genetics, and evolution. pp 359-386 Academic Press, San Diego, California

Toloza A, Vassena C, Gallardo A, González-Audino P, Picollo MI (2009) Epidemiology of pediculosis capitis in elementary schools of Buenos Aires, Argentina. Parasitol Res 104:1295-1298. https:// doi.org/10.1007/s00436-008-1324-6

Toloza AC, Ascunce MS, Reed D, Picollo MI (2014) Geographical distribution of pyrethroid resistance allele frequency in head lice (Pediculus humanus capitis) from Argentina. J Med Entomol 51: 139-144. https://doi.org/10.1603/ME13138

Toloza AC, Laguna MF, Ortega Insaurralde I, Vassena C, Risau-Gusman S (2018) Insights about head lice transmission from field data and mathematical modeling. J. Med. Entomol. 55:929-937. https://doi. org/10.1093/jme/tjy026

WHO. WHO Director-General's opening remarks at the media briefing on COVID-19 [Internet]. 2020 [cited 2020 Jul 8]. Available from: https://www.who.int/dg/speeches/detail/whodirectorgeneral-s- opening-remarks-at-the-media-briefing-on-covid-19-11-march2020

Willems S, Lapeere H, Haedens N, Pasteels I, Naeyaert JM, De Maeseneer J (2005) The importance of socio-economic status and individual characteristics on the prevalence of head lice in schoolchildren. Eur j dermatol 15:387-392

Williams LK, Richert A, MacKenzie WR, Hightower AW, Blake PA (2001) Lice, nits, and school policy. Pediatrics 107:1011-1015. https://doi.org/10.1542/peds.107.5.1011

Zhu N, Zhang D, Wang W, Li X, Yang B, Song J, Zhao X, Huang B, Shi W, Lu R, Niu P, Zhan F, Ma X, Wang D, Xu W, Wu G, Gao GF, Tan W, China Novel Coronavirus Investigating and Research Team (2020) China Novel Coronavirus Investigating and Research Team. A novel coronavirus from patients with pneumonia in China. N Engl J Med 382:727-733. https://doi.org/10.1056/NEJMoa2001017

Publisher's note Springer Nature remains neutral with regard to jurisdictional claims in published maps and institutional affiliations. 